Review

\title{
Ocoxin as a complement to first line treatments in cancer
}

\author{
Aitor Benedictoํㅡ, Eduardo Sanz², Joana Márquez ${ }^{\circledR}$ \\ 1. Department of Cellular Biology and Histology, School of Medicine and Nursing, University of the Basque Country, 48940, Leioa, Bizkaia, Spain. \\ 2. Catalysis S.L., Toledo, Spain. \\ $\square$ Corresponding author: Dr Joana Márquez, Department of Cell Biology and Histology, School of Medicine and Nursing, University of the Basque Country, \\ 48940, Leioa, Bizkaia, Spain. E-mail: joana.marquez@ehu.es. \\ () The author(s). This is an open access article distributed under the terms of the Creative Commons Attribution License (https://creativecommons.org/licenses/by/4.0/). \\ See http://ivyspring.com/terms for full terms and conditions.
}

Received: 2020.06.30; Accepted: 2020.11.25; Published: 2021.01.01

\begin{abstract}
Chemotherapy and radiotherapy are the most frequent treatment for patients suffering from malignant progression of cancer. Even though new treatments are now being implemented, administration of these chemotherapeutic agents remains as the first line option in many tumor types. However, the secondary effects of these compounds represent one of the main reasons cancer patients lose life quality during disease progression. Recent data suggests that Ocoxin, a plant extract and natural compound based nutritional complement rich in antioxidants and anti-inflammatory mediators exerts a positive effect in patients receiving chemotherapy and radiotherapy. This mixture attenuates the chemotherapy and radiotherapy-related side effects such as radiation-induced skin burns and mucositis, chemotherapy-related diarrhea, hepatic toxicity and blood-infection. Moreover, it has been proven to be effective as anticancer agent in different tumor models both in vitro and in vivo, potentiating the cytotoxic effect of several chemotherapy compounds such as Lapatinib, Gemcitabine, Paclitaxel, Sorafenib and Irinotecan. The aim of this review is to put some light on the potential of this nutritional mixture as an anticancer agent and complement for the standard chemotherapy routine.
\end{abstract}

Key words: Ocoxin; natural product; antioxidant; anti-inflammatory; cancer; chemorresistance; coadjuvant

\section{Introduction}

Cancer patients diagnosed with primary and metastatic malignancies are treated with radiotherapy (RT) and a diverse group of chemical compounds, chemotherapeutics, which have been shown to be effective in controlling disease progression and, in some scenarios, eradicating the tumor mass [1-4]. Even though new successful treatment opportunities are now being implemented in several cancer types, such as immunotherapy for melanoma, colorectal cancer and hematological malignancies among others [5-7], the chemotherapy (CT) agents remain as the first option for many malignancies and a complement for those patients receiving immunotherapy regimens [8-10]. CT has been the only effective option for decades and its benefits are unquestionable. However, patients taking advantage from this treatment report a wide range of negative side effects that limit their life. One of the main goals of oncologist is to cope with the disease but providing good quality of life to cancer patients.
The use of a diverse spectrum of nutritional compounds is a common complement for patients receiving $\mathrm{CT}$ and $\mathrm{RT}$, including antioxidants, anti-inflammatory mediators and vitamins [11-16]. Antioxidants are one of the most routinely used complement, with moderately good results when dealing with treatment derived complications. To this respect, melatonin was proven effective in reducing the oral mucositis, which drives oral tissue inflammation and pain in head and neck cancer patients receiving CT and RT [17]. A high spectrum of antioxidants was proven to be effective dealing with CT-induced peripheral neuropathy (CINP) in patients suffering from Colorectal Cancer. Several studies reported attenuated CINP in patients receiving N-acetylcysteine, Goshajinkigan (GJG or TJ-107), a traditional Japanese herbal extract and Jianwei Hiangqi Guizhi Wuwu Decoction (JHGWD) a traditional Chinese medicine herbal extract, while receiving CT treatment with Oxaliplatin [18-20]. 
Furthermore, the antioxidant effect of Sodium thiosulfate (STS) seems to be positive to revert a critical side effect of cisplatin treatment, as reduced hearing loss in head and neck cancer patients was recently reported [21].

Ocoxin, also known as Oncoxin or Ocoxin Oral solution, is an orally bioactive nutritional mixture composed by antioxidant and anti-inflammatory natural ingredients (Table 1) (Catalysis S.L), rich in green tea polyphenols, such as epigallocatechin-3 gallate, glycyrrhizic acid, cinnamic acid and vitamin B6. These compounds have shown a positive effect when tested against cancer, reducing cancer stem cell markers in colon cancer and related to decreased colorectal cancer risk in humans [22-24]. Some Ocoxin ingredients such as glycyrrhizinic acid and previously mentioned green tea polyphenols exert immunomodulatory and anti-inflammatory functions [25-28], which may affect significantly to the positive response to this nutritional complement. Recent evidences describe the synergic effect of Ocoxin ingredient Ascorbic acid against lymphoma when combined with immunotherapy [29], thus, reinforcing the hypothesis that Ocoxin may act sinergically when administered with routinely used cytotoxic agents.

Table 1. Ingredient composition of Ocoxin

\begin{tabular}{ll}
\hline Average values (per 100 ml) & \\
\hline Glycine & $2.000 \mathrm{mg}$ \\
Glucosamine & $2.000 \mathrm{mg}$ \\
Malic Acid & $1.200 \mathrm{mg}$ \\
Arginine & $640 \mathrm{mg}$ \\
Cysteine & $204 \mathrm{mg}$ \\
monoammonium glycyrrinate & $200 \mathrm{mg}$ \\
Ascorbic Acid & $120 \mathrm{mg}$ \\
Zinc Sulfate & $80 \mathrm{mg}$ \\
Green tea extract & $25 \mathrm{mg}$ \\
calcium pantothenate & $12 \mathrm{mg}$ \\
Piridoxine & $4 \mathrm{mg}$ \\
Manganese sulphate & $4 \mathrm{mg}$ \\
cinnamon extract & $3 \mathrm{mg}$ \\
Sodium Benzoate & $100 \mathrm{mg}$ \\
Potasium Sorbate & $100 \mathrm{mg}$ \\
Maracuya Aroma & $50 \mathrm{mg}$ \\
Sucralose & $24 \mathrm{mg}$ \\
Folic Acid & $400 \mu \mathrm{gg}$ \\
cyanocobalamin & $2 \mu \mathrm{g}$ \\
\hline
\end{tabular}

Evidences obtained during the last decade uncover the role of Ocoxin in improving the life quality of CT receiving cancer patients. Moreover, preclinical models of different cancer types point out Ocoxin as an effective anticancer agent and a good candidate to be tested as a complement for the CT and $\mathrm{RT}$ routines in the clinical practice.

The aim of this review is to focus on the reported positive effects of Ocoxin during routine clinical cancer treatments and the effectiveness of using
Ocoxin as anticancer compound and adjuvant for the $\mathrm{CT}$ and $\mathrm{RT}$ regimens.

\section{Ocoxin mitigates CT-related side effects in clinical trials}

While fighting against cancer, patients receiving doses of CT have to deal with different complications related to the treatment. These complications include depression, loss of appetite and the consequent weight loss, diarrhea, interrupted treatment routine due to the adverse effects and inflammation of the oral cavity. There are several nutritional complements that help mitigating these side effects, which influence both the quality of life of cancer patients and determine the viability of the established treatment length [12]. The composition of Ocoxin, rich in natural compounds with well-known antioxidant and anti-inflammatory effects, may give rise to improved CT-related response. Moreover, it is to note that Ocoxin has shown good results when administered as an adjuvant regimen in patients receiving CT. Even though there is still a lack of studies regarding Ocoxin bioavailability and metabolization, the observed benefits may encourage researchers to go into deep into these processes, in order to understand and apply this compound to a wide spectrum of patients.

\section{Ocoxin administration routine}

The administration of Ocoxin along the different clinical studies conducted is specified in Table 2. Briefly, all patients undergoing CT and RT routines were supplemented with 50 or $75 \mathrm{ml}$ oral Ocoxin from the beginning of the anticancer treatment until the end of the RT and CT cycles. In one clinical study Ocoxin supplementation started one month before the anticancer treatment and was sustained for one month after the conclusion of RT and CT routines. Ocoxin was administered for 3 weeks after the conclusion of the standard treatments in another clinical study. The Ocoxin administration spectrum and anticancer treatment implemented for each clinical study is specified in Table 2.

\section{Ocoxin and depression}

Depression is a common undesired side effect of CT regimens. Interestingly, increased degrees of oxidative stress, which is one of the catalyzators of the antitumor effect of $\mathrm{CT}$, are associated with depression and anxiety symptoms [30]. It is to note that Ocoxin when administered to cancer patients improved their quality of life [31, 32], which was accompanied by an increased optimism, therefore, reducing the number of episodes of depression [31]. Moreover, Kaidarova et al. (2019) described improved quality of life along with increased well-being in patients receiving 
Ocoxin supplementation, compared to that of patients without Ocoxin [33]. It is tempting to hypothesize that the antioxidant potential of Ocoxin could be critical for this reported improvement. Moreover, this finding goes in line with previous reports on the use of a wide spectrum of compounds with antioxidant effects to treat human depression, such as resveratrol [34]. Regarding to preclinical evidences, the same therapeutic effect was reported in different mice models, where a reduction in the depressive behavior was observed due to the reduction on the oxidative stress [35-37]. Along with oxidative stress, inflammation has also been postulated as one the promoters of depression [38]. In fact, it is related to depression observed in patients suffering from other nervous system pathologies, such as multiple sclerosis [39]. One of the standard treatments to cope with depression is the use of antidepressants. These psychoactive drugs exert their effect in part through the reduction of the production of pro-inflammatory cytokines such us interleukin-1 $\beta$ (IL-1 $\beta$ ), interleukin-6 (IL-6) and tumor necrosis factor a (TNF- $\alpha$ ) [40, 42], therefore, modulating immune responses. Interestingly, natural compounds such as curcumin and salidroside have shown antidepressant effect in stress-induced depression with reported decreased inflammatory IL-6 and TNF-a signals $(42,43]$, driving to immune regulation. A similar response was observed in patients suffering from other pathologies under Ocoxin regimen, reporting immunoregulatory properties and reducing TNF-a level [25]. Consequently, Ocoxin may alleviate depression in cancer patients reducing the inflammatory status and the oxidative stress mediated damage.

\section{Ocoxin and Karnofsky index}

The Karnofsky Performance Scale Index is a measurement tool to assess the functional impairment of patients. The aim of this index is to assess the prognosis of patients, which allows comparing different therapies and treatments. Petients with higher Karnofsky index show better prognosis. It is to note that Ocoxin administration along with CT resulted in 59,26\% increase in Karnofsky index compared to 30,38 reported in patients receiving CT alone, suffering from different neoplasic diseases, such as head and neck, breast and uterine cervix cancer [31]. In concordance, other natural compounds have shown efficacy when using as adjuvant along with CT regimens, increasing the Karnofsky index in cancer patients, such as those suffering from Non Small Cell Lung Cancer (NSCLC) [44]. Therefore, this effect may be mediated by the overall improvement in health status and self-steem observed in patients receiving daily dose of Ocoxin as coadjuvant to CT.

\section{Ocoxin improves $\mathrm{CT}$ and $\mathrm{RT}$ related toxicity}

The chemotherapeutic anticancer treatments cause a significant toxicity to patients, limiting their ability to tolerate the established routine for the treatment of the diagnosed malignancies. Ocoxin has shown a positive effect in mitigating CT-related toxicity, allowing patients to tolerate better the RT. In fact, Ocoxin reduced the number and the intensity of adverse episodes in head and neck, breast and uterine cervix cancer patients [31]. These results were recently confirmed by Chon-rivas et al. (2018) in head and neck cancer [45]. They reported decreased RT interruptions and lower side effects related to CT and RT toxicity. Almost $50 \%$ of the anticancer drugs approved by the FDA mediate the production of reactive oxygen species (ROS) or reactive nitrogen species (RNS) [44], therefore, affecting dramatically the function of healthy cells. Interestingly, antioxidant and anti-inflammatory properties of Ocoxin may be behind this improved tolerance to anticancer therapies.

Table 2. Clinical studies reporting significant benefits in patients receiving Ocoxin (Oncoxin) as coadjuvant for routine anticancer treatments

\begin{tabular}{llll}
\hline Reference & Cancer type & Reported benefits & Dose and regimen \\
\hline 31 & Head and neck cancer; & Reduced depression cases; & CT+RT; \\
& Breast cancer; & Increased optimism; & 50 ml Oncoxin/day for 1 year \\
& Uterine cervix cancer & Reduced CT-related toxicity; & \\
& & Fewer treatment interruptions; & \\
& Increased patient weight; \\
& & Reduced radiation side effects; & \\
61 & Increased survival rate & \\
& HCC & Increased patient survival; & No other treatment; \\
& & Increased appetite & 50 ml day of Oncoxin (3 months) \\
& Head and Neck cancer & Reduced RT interruptions; & CT + RT; \\
& & Reduced RT-CT toxicity & 75 ml day Oncoxin-Viusid (30 days prior, during \\
& & & treatment and 30 days after treatment) \\
& Gastric cancer; & Improved quality of life; & CT + RT; \\
& NSCLC & Increased body mass; & 50 ml Oncoxin/day for 20 days \\
\hline
\end{tabular}




\begin{tabular}{|c|c|c|c|}
\hline & & $\begin{array}{l}\text { Improved hepatic function; } \\
\text { Reduced hepatic toxicity }\end{array}$ & \\
\hline 55 & Malignant neoplasms & $\begin{array}{l}\text { Reduced hepatic toxicity; } \\
\text { Improved oral mucositis; } \\
\text { Increased food intake }\end{array}$ & $\begin{array}{l}\text { CT + RD; } \\
50 \mathrm{ml} \text { Oncoxin/day for } 20 \text { days }\end{array}$ \\
\hline 32 & Cervical cancer Endometrial Adenocarcinoma & $\begin{array}{l}\text { Improved hepatic function; } \\
\text { Reduced hepatic toxicity; } \\
\text { Reduced adverse effects; } \\
\text { Improved quality of life }\end{array}$ & $\begin{array}{l}\mathrm{CT}+\mathrm{RT}+\mathrm{BT} \\
75 \mathrm{ml} \text { Oncoxin Viusid/daily from the beginning of } \\
\text { CT treatment until } 3 \text { weeks after CT routine end. }\end{array}$ \\
\hline
\end{tabular}

To this respect, one of the side effects, CT-induced cognitive impairment (CICI), also known as "chemobrain" or "chemofog" is partly mediated by the ROS and reactive nitrogen species (RNS) produced by $\mathrm{CT}$, inducing neuron death [46]. This neuronal death might be partially inhibited by the antioxidant effect of Ocoxin, conferring the patient a better cognitive and health status.

CT-induced diarrhea (CID) is considered a reliable toxicity parameter in patients receiving $\mathrm{CT}$ [47]. CID is a usual side effect of several CT agents such as Sorafenib and Irinotecan. With respect to Irinotecan, the most studied agent regarding to side effects, it is provoked by the intestinal cell damage through 7-Ethyl-10-hydroxycamptothecin (SN-38) metabolite. SN-38 can induce ROS in healthy cells, as reported in hepatocytes increasing ROS plasma levels of Irinotecan receiving cancer patients [48]. Moreover, epithelial intestinal cells (IEC) enter DNA damage-mediated apoptosis process, which leads to ROS production [49]. This ROS cause severe damage to IEC, promoting both inflammation and epithelial basal cell death leading to diarrhea. It is tempting to hypothesize that the antioxidant activity of Ocoxin may inhibit this ROS-mediated mechanism in the intestinal track, reducing CID. Moreover, Ocoxin mediated anti-inflammatory potential may reduce gastrointestinal inflammation, mitigating diarrhea symptoms, as reported using a Cyclooxigenase-2 inhibitor, Celecoxib [50].

Oral mucositis is a severe inflammation of the oral cavity leading to oral pain and ulcerative area presented in almost all patients receiving $\mathrm{RT}$ and in 40 $\%$ of the patients receiving CT $[51,52]$. This damage is partly mediated by inflammatory mediators such as IL-1 $\beta$, TNF- $\alpha$ and inducible nitric oxidase sinthase (iNOS) $[53,54]$. Interestingly, Ocoxin exerts a curative effect in patients suffering from this side effect, diminishing the ulcerative area and facilitating the healing of the affected tissue [55], therefore eliminating the pain related to eating and drinking. This effect may be due to the anti-inflammatory properties of Ocoxin, which confers the ability to inhibit TNF-a upregulation, as reported in other pathologies [25]. It is tempting to hypothesize that this effect may be mediated by Glucosamine present in Ocoxin, since its supplementation leads to downregulation of nuclear factor kappa-light-chainenhancer of activated B cells $(\mathrm{NF}-\mathrm{k} \beta)$, which in turn decreased inflammatory mediators such as IL-1 $\beta$ and TNF- $\alpha$ [56]. On the other hand, antioxidant potential of Ocoxin may block the synthesis of ROS and NOS during mucositis, in concordance with other findings reporting improved oral pathology using natural compounds with antioxidant and anti-inflammatory properties [57, 58].

In line with this observation, the supplementation with epigallocatechin-3-gallate (EGCG), one of the main ingredients of Ocoxin, has proven effective to mitigate CT and RT induced inflammatory disorders in patients suffering from other cancers $[59,60]$. Therefore, Ocoxin seems to improve the quality of life of patients, as reported by Kaidarova et al. (2019) in patients receiving adjuvant CT [33]. Using Ocoxin as a complement for the CT regimen of gastric cancer and NSCLC patients (XELOX and paclitaxel+carboplatin respectively), they observed improved quality of life, along with increased body mass, appetite and albumin levels. Interestingly, Ocoxin almost eradicated the hepatic toxicity of CT regimens in those patients, maintaining alanine aminotransferase (ALT) and aspartate aminotransferase (AST) levels unchanged in 80 to $90 \%$ of the subjects. Moreover, clinical trials are now running for the evaluation of Ocoxin as a CT complement to confirm not only its beneficial potential to improve mucositis but also to increase patient appetite and body mass (ClinicalTrials.gov Identifier: NCT03577535).

\section{Ocoxin increases patient survival}

To improve cancer patient's life quality represents a very significant positive effect of Ocoxin. However, this compound seems to prolong patient's life expectancy in combination with routine CT regimen. Al-Mahtab et al, (2015) reported a significant increase in terminal stage hepatocellular carcinoma (HCC) patient's life expectancy. All the patients from control group receiving CT suffering from HCC died within 2 months, while $52 \%$ of adjuvant Ocoxin supplemented patients died the first two months of the study. Interestingly, $26 \%$ of Ocoxin supplemented patients lived for another 3 months, while $21 \%$ of Ocoxin having individuals prolonged their life for 9 
months [61]. This observation goes in line with that reported by Uddin et al. (2018), observing increased survival rates in Ocoxin receiving patients from head and neck, breast and uterine cervix cancer compared to control group $(87,65 \%$ vs $74,68 \%$, respectively) [31], always under CT routine. In line with these findings, clinical trials using Melatonin as adjuvant to CT resulted in 1 year increased survival rate while promoting the regression of tumors [62]. The same effect was reported using melatonin in combination with cisplatin and etoposide for NSCLC, improving tumor regression and increasing 6\% the 5-year survival rate [63]. It is tempting to hypothesize that the antioxidant and anti-inflammatory effect of Ocoxin reverts the undesired side effects of $\mathrm{CT}$, which leads to improved overall physiology of patients undergoing anticancer treatments, prolonging their life expectancy.

Immune response modulation is a common step during cancer [64, 65], and plays a critical role in disease progression. In fact, the inhibition of the antitumor immune response represents one of the hallmarks of cancer development $[66,68]$. It is to note that Ocoxin has an immune activation effect, which is the opposite effect mediated by both tumor and tumor-activated stromal cells in the tumor microenvironment $[64,65,68]$. Therefore, the activation of the immune response, along with the antioxidant and anti-inflammatory properties of Ocoxin may lead to reported increased survival in HCC, head and neck, breast and uterine cervix cancer patients.

Which is still to be deciphered is the direct antitumor effect of Ocoxin in cancer patients. Interestingly, a significant anticancer effect has been observed in different preclinical in vitro and in vivo cancer models. These preclinical models have proven a synergic effect of Ocoxin with a wide spectrum of CT agents in vitro and in vivo, even reverting stromal-mediated chemorresistance.

\section{Evidences of the positive effect of Ocoxin in the liver metabolism in patients under CT regimens}

One of the main organs suffering from CT routines is the liver. This organ is the responsible of metabolizing anticancer drugs, making the liver function monitoring a required measure [69]. Decreased albumin levels reflect liver damage. Moreover, the National Cancer Institue (NCI) assessed liver damage based on the increased serum levels of liver enzymes ALT, AST, alkaline phosphatase (ALP), and $\gamma$-glutamyltransferase (GGT) [69]. Clinical studies using Ocoxin as coadjunvant for gastric cancer revealed a significant improvement regarding liver toxicity when combined with adjuvant
CT. Ocoxin supplementation led to increased serum albumin levels compared to non-supplemented adjuvant CT receiving group [32]. Besides, Ocoxin abrogated hepatic-toxicity related ALT and AST enzyme increase in $92 \%$ of the patients under adjuvant CT regiment after 3 weeks of treatments, while only the AST and ALT levels of $50 \%$ of the patients from non-supplemented group remained unchanged. This reduced hepatic toxicity was further confirmed by Shumsky et al. (2019) in patients receiving Ocoxin to mitigate $\mathrm{CT}$ and $\mathrm{RT}$ related oral mucositis [55]. They reported 4 and 7-fold reduced ALT and AST levels in patients under Ocoxin supplementation compared to those receiving $\mathrm{CT}$ and RT. It is tempting to hypothesize that increased ROS levels, which are a common product of drug-mediated hepatic toxicity [70], damage liver cells, leading to liver toxicity. Therefore, the antioxidant effect of Ocoxin may prevent hepatic tissue damage, as observed with several antioxidants, such as glyzirrinic azid, one of the components of Ocoxin [71, 72].

\section{Ocoxin mitigates the negative effects in hemoglobin and leukocyte counts in patients under CT regimens}

CT treatments have severe impact in the hemoglobin levels of individuals receiving these drugs, leading to anemia [73]. Different antioxidants have shown positive effects in hemoglobin levels during anticancer treatments [74]. In line with these findings, Ocoxin supplementation reduced this side effect, diminishing hemoglobin toxicity in $80 \%$ of the patients receiving adjuvant CT. However, only $58 \%$ of patients receiving adjuvant CT treatment without coadjuvant Ocoxin showed no toxicity [32]. Similar results were reported in cervical cancer and endometrial carcinoma patients receiving Ocoxin as coadjuvant for CT routines. Ocoxin mitigated the decrease in hemoglobin concentration upon treatment with adjuvant CT, RT and brachytherapy [32]. Interestingly, Ruiz-Lorente et al. (2020) concluded that Ocoxin was efficient in mitigating the reduction in platelet and leukocyte counts in the blood of adjuvant $\mathrm{CT}$ receiving patients, compared to that of adjuvant $\mathrm{CT}$ receiving patients with no Ocoxin supplementation [32].

\section{The antitumor effect in preclinical in vitro and in vivo models of Ocoxin}

As previously mentioned, there is an increasing need to find new strategies to improve sensitivity to CT and to prevent the produced side effects on patients undergoing anticancer treatments. Natural 
products are being implemented with promising results as coadjuvant for $\mathrm{CT}$, not only for their positive effect in mitigating side effects but also for their anticancer action. To this respect, Ocoxin is a mixture of several natural compounds, which has proven benefits treating cancer individually. Several in vitro studies carried out on murine and human cell lines of different cancer types, such as breast, liver metastasis of colorectal cancer, acute myeloid leukemia (AML), liver, lung, pancreatic cancer and glioblastoma demonstrated that Ocoxin reduces tumor cell viability in a dose dependent manner (Table 3) [75-81].

This cytotoxicity of Ocoxin against tumor cells is triggered, in part, by increasing apoptosis and decreasing the proliferation of tumor cells [75-77]. Supporting these results, different biological compounds, such as, flavonoids, green tea and curcumin among others, have demonstrated antitumor effects through the induction of growth arrest and apoptosis of cancer cells [82-84]. It has been shown that Ocoxin slows down cell cycle of tumor cells by arresting cells on G2/M phase in case of breast and SCLC and increasing cell population on Sub G1 and decreasing in S phase in case of colorectal carcinoma $[75,79,76]$. Supporting these observations, genistein, a soy-derived isoflavone induced cell cycle arrest at G1 and/or S phase in certain cancer cell lines and it is known to inhibit cancer cell growth through G2/M inhibition in cancer cells [85, 86]. Furthermore, Cianfruglia et al. (2019) reported that curcumin extract, which has the ability to suppress cell proliferation, induced apoptosis, inhibited angiogenesis and suppressed the expression of antiapoptotic proteins, inhibited cell proliferation by G2/M cell-cycle phase arrest [87-91]. The same effect was uncovered using genistein. Genistein arrested the cell cycle of human urinary bladder carcinoma on G2/M phase by the down-regulation of cyclin A and cyclin B1, and up-regulation of Cdk inhibitor p21 [92]. Ocoxin seems to carry out cell cycle arrest by increasing the levels of the cell cycle inhibitor p27 protein and decreasing the cell cycle regulator cyclin $\mathrm{D} 1$ and the tumor suppressor $\mathrm{pRb}$ protein levels [75, 77, 79].

Furthermore, natural products are used as a coadjuvant therapy to improve and increase the tumor cell sensitivity to CT [93]. To this regard, vincristine is used to treat acute lymphocytic lymphoma and neuroblastoma. Bahmani et al. (2018) described that Centaurea albonitens extract enhance the cytotoxicity of vincristine without increasing normal cell toxicity [94]. Moreover, 5-fluorouracil (5-FU) is a $\mathrm{CT}$ used to treat several cancer types, such as, gastric, breast, liver and prostate [88-90]. In this way, curcumin and green tea, among others, have demonstrated efficacy by increasing the sensitivity of cancer cells and reducing the produced cytotoxicity $[98,99]$. In this way, the co-treatment of curcumin and 5- FU/oxaliplatin increased their synergistic antitumor efficacy in gastric cancer by activating the caspase 3, caspase 8 and 9 expression [99]. Moreover, the combination of curcumin with cisplating demonstrated a potent synergistic effect by activating caspase 3 in ovarian cancer [100]. Interestingly, Ocoxin increased in vitro the cytoxicity of first line chemoterapeutic agents, such as, irinotecan, paclitaxel, gemcitabine, Ara C, doxorubicin, fludarabine, sorafenib, docetaxel, vincristine, lapatinib and cisplatin by increasing the apoptosis of cancer cells [75, 77-81]. However, Ocoxin did not demonstrate any synergic effect with trastuzumab [75]. Furthermore, Ocoxin reduced the side effects produced by chemoterapy in mice [71], which is in line with described improved health status of patients treated with Ocoxin and with several studies carried out in animal models using natural compounds as coadjuvants [101,102].

Nowadays one of the major challenges to treat cancer is to fight resistance to the CT. This chemoresistance may be produced by the tumor host factors [103] or factors associated with tumor-tumor microenvironment interactions [104]. The implication of the tumor microenvironment on the progression of the tumor and the chemoresistance nowadays is widely recognized [105-110]. The tumor microenvironment consists of tumor cells, vasculature, extracellular matrix (ECM), non-malignant cells, such as, stromal cells, tumor associated fibroblast (CAFs), immune cells and a complex signaling molecule network which include growth factors, cytokines, chemokines, and exosomes that sustain the internal connections of the microenvironment, [111,112]. Interestingly, Ocoxin modulates the tumor microenvironment through several pathways (Figure 1).

CAFs, among others, participate in the development of tumor angiogenesis, metastasis, and chemo-resistance [112-114]. Moreover, CAFS secrete collagen that regulates the chemotherapeutic drug resistance of cancer cells [115]. Thus, the actual treatments could be directed not only to the tumor cells but also to block the interaction between CAFs and cancer cells to avoid the chemorresistance of the tumor. Interestingly, Ocoxin reverted the chemorresistance effect produced by CAFs on human pancreatic cells in vitro [81]. Moreover, hepatic stellate cells (HSCs) are hepatic myofibroblast-like cells that infiltrate the tumor and develop a pro-tumoral environment [116]. HSC burst liver metastasis through different mechanisms, such as, collagen 
deposition, immune suppressor cell recruitment and endothelial cell migration [117-120]. Interestingly, Ocoxin reduced the HSC infiltration into the tumor stroma of colorectal cancer liver metastasis, which was accompanied with decreased tumor burden [76]. This effect may be mediated by the reduction of inflammatory cytokines such as IL-6 and IL-1 $\beta$, known to promote tumor growth, HSC mediated proliferation and increased ECM deposition. In fact, a similar reduction was reported in pancreatic cancer treated with conophylline, a plant derivate, where protumoral CAF effect was diminished [121].

As mentioned above, inflammation has been widely linked to cancer progression. In this way, one of the main source of inflammatory mediators in the tumor microenvironment are macrophages, cells of the innate immune system, which invade the precancerous tissue, and secrete factors to promote the tumor growth and metastasis [122,123]. Due to the anti-inflammatory properties of some natural products, their role as new and complementary treatments is being tested. For example, green tea extract administered to mice with nonalcoholic steatohepatosis has shown to inhibit the early oncogenic response [124]. In line with this results, Ocoxin regulated the cytokine milieu during liver colonization, decreased the pro-inflammatory IL1 $\beta$, interferon gamma (IFNY) and TNFa cytokine expression while reduced the macrophage infiltration into the tumor stroma and [76-78]. In fact, in concordance with this observation, Ocoxin impaired the polarization of macrophages into the proinflammatory $\mathrm{M} 2$ phenotype in a murine glioblastoma model, along with reduced tumor growth [125]. This effect may be mediated by the antioxidant effect of Ocoxin, which decreases ROS in macrophages in vitro, known to play an important role for M2 differentiation [126]. This result is in line with the use of chlorogenic acid in glioblastoma, with a potent antioxidant properties, that showed reduced tumor growth, mediated by a repolarization of M2 macrophages into M1 [127]. Moreover, several antioxidants such as caffeic acid and butylated hydroxyl-anisole (BHA) have shown similar effects impeding M2 polarization. Therefore, Ocoxin impairs stromal cell recruitment affecting the generation of a proinflammatory and proangiogenic microenvironment.

Table 3. Preclinical studies reporting antitumor effects of Ocoxin and synergic effect with a wide variety of anticancer drugs

\begin{tabular}{|c|c|c|c|}
\hline Reference & Cancer type & In vitro results & In vivo results \\
\hline 75 & HER2+ Breast cancer & $\begin{array}{l}\text { Reduced proliferation; } \\
\text { Increased apoptosis; } \\
\text { Cell cycle arrest; } \\
\text { Synergy with Lapatinib }\end{array}$ & Decreased tumor volume \\
\hline 76 & CRC & $\begin{array}{l}\text { Reduced viability; } \\
\text { Reduced migration; } \\
\text { Cell cycle arrest }\end{array}$ & $\begin{array}{l}\text { Reduced liver metastasis; } \\
\text { Increased CRC apoptosis; } \\
\text { Reduced proliferation; } \\
\text { Reduced CAF infiltration }\end{array}$ \\
\hline 77 & Acute Myeloid Leukemia & $\begin{array}{l}\text { Reduced proliferation; } \\
\text { Cell cycle arrest; } \\
\text { Synergy with Ara C; } \\
\text { Dexorubicin and Fluradabine }\end{array}$ & $\begin{array}{l}\text { Reduced tumor volume; } \\
\text { Reduced AML proliferation }\end{array}$ \\
\hline 79 & $\mathrm{HCC}$ & $\begin{array}{l}\text { Reduced HCC proliferation; } \\
\text { Synergy with Sorafenib; } \\
\text { Cell cycle retardation }\end{array}$ & Reduced HCC proliferation \\
\hline 78 & CRC & $\begin{array}{l}\text { Reduced CRC viability; } \\
\text { Synergy with Irinotecan }\end{array}$ & $\begin{array}{l}\text { Reduced liver metastasis; } \\
\text { Increased CRC apoptosis; } \\
\text { Reduced CRC proliferation; } \\
\text { Reduced TAM infiltration; } \\
\text { Synergy with Irinotecan regarding CRC proliferation }\end{array}$ \\
\hline 80 & SCLC & $\begin{array}{l}\text { Reduced SCLC proliferation; } \\
\text { Synergy with vincristine and docetaxel; } \\
\text { Increased cell death; } \\
\text { Cell cycle retardation }\end{array}$ & $\begin{array}{l}\text { Reduced tumor volume; } \\
\text { Increased SCLC apoptosis; } \\
\text { Reduced SCLC proliferation; } \\
\text { Downregulation of angiogenesis-related genes in vivo in SCLC }\end{array}$ \\
\hline 81 & Pancreatic cancer & $\begin{array}{l}\text { Reduced cell viability; } \\
\text { Cell cycle retardation; } \\
\text { Synergy with Paclitaxel and Gemcitabine; } \\
\text { Reduced fibroblast-mediated chemorresistance }\end{array}$ & Reduced tumor markers \\
\hline 125 & Glioblastoma & $\begin{array}{l}\text { Reduced GBM viabity; } \\
\text { Reduced CSC renewal ability; } \\
\text { Impaired macrophage polarization to M2 }\end{array}$ & $\begin{array}{l}\text { Reduced GBM tumor growth; } \\
\text { Impaired macrophage polarization to M2 }\end{array}$ \\
\hline
\end{tabular}



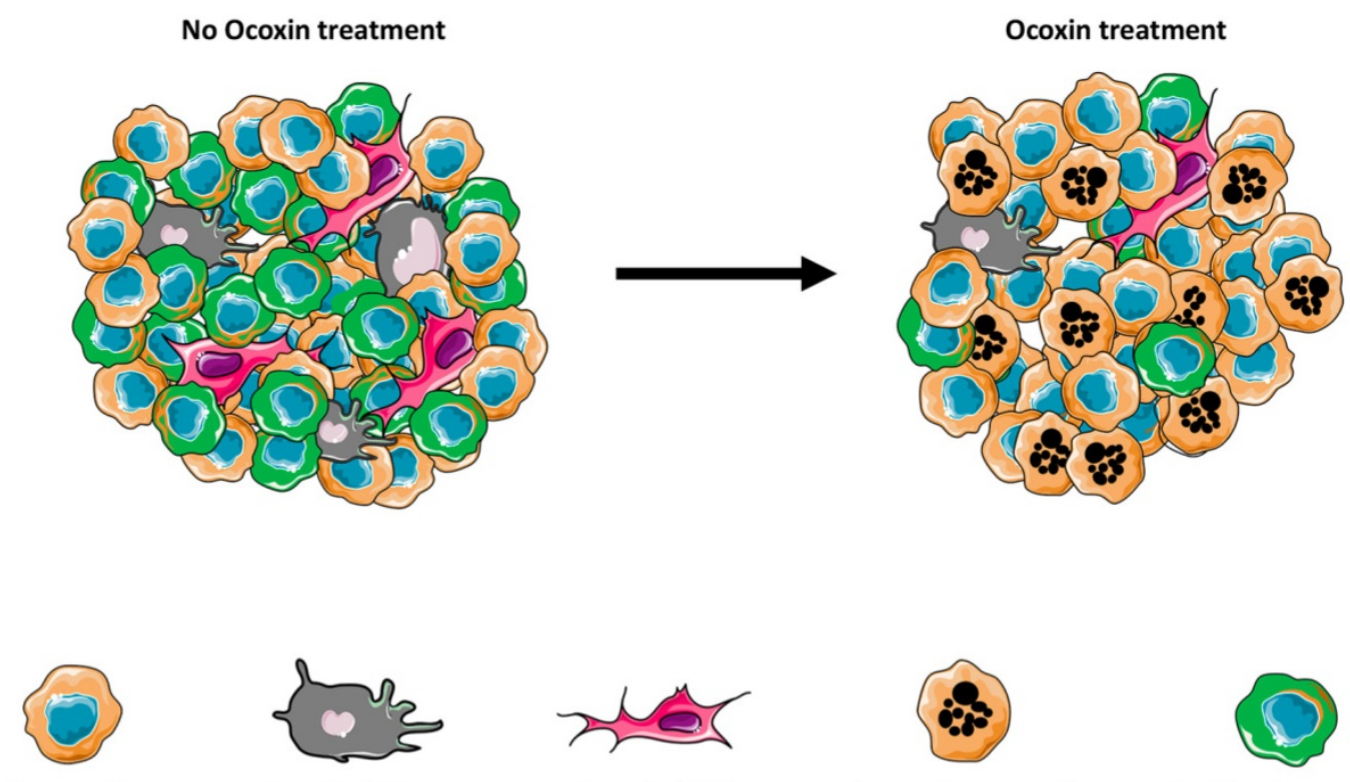

Recruited CAFs

Apoptotic tumor cell

Proliferating tumor cell

Figure 1. Ocoxin modulates the tumor microenvironment. Ocoxin treatment reduces the recruitment of tumor-promoting macrophages and fibroblasts into the developing tumor. Moreover, Ocoxin impairs reduces cell proliferation and increases apoptotic cancer cell death, leading to impaired tumor growth.

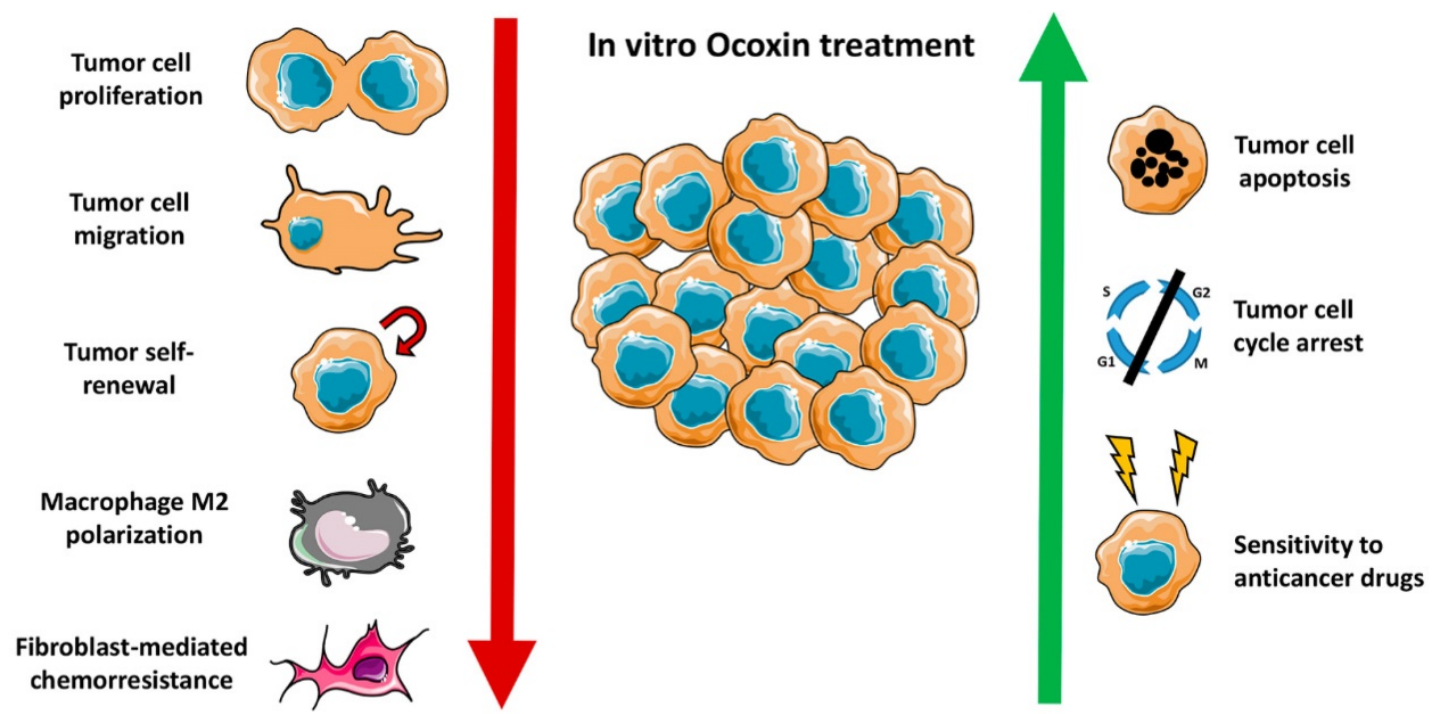

Figure 2. Ocoxin exerts a wide spectrum of anticancer effects in vitro. On the one hand, reduces tumor cell proliferation and migration, tumor self-renewal potential, macrophage M2 polarization and the protective effect of fibroblasts in tumor cells exposed to anticancer drugs. On the other hand, increases tumor cell death by apoptosis, cell cycle arrest and sensitizes tumor cells to chemotherapy agents.

In summary, Ocoxin impairs tumor development through a wide spectrum of antitumor effects (Figure 2). On the one hand, Ocoxin increased the cytotoxicity of anticancer agents and reduced the migration capacity of tumor cells. On the other hand, Ocoxin regulated the tumor microenviroment, by reducing the recruitment of different pro-tumoral cells and making the tumor more vulnerable and sensitive for CT.

\section{Conclusion and future perspectives}

The efficacy of the anticancer treatments and, therefore, the subsequent healing process of patients are strongly influenced by the nutritional state [12].
Taking into account that malnutrition is directly related to patient death when dealing with cancer malignancies, natural products and complements that could alleviate this physical condition should be considered as part of the treatment routine. Moreover, natural products with antioxidant and antiinflammatory effect such as Ocoxin have been proven to be effective improving CT-related side effects and bursting antitumor effect of a wide spectrum of anticancer drugs. Therefore, if the ongoing clinical trials support these effects in patients suffering from different cancers, Ocoxin may be considered a good candidate as a complement of the routinely used RT and CT regimens. 


\section{Authors' Contributions}

$\mathrm{AB}$ and JM wrote the review. ES helped with the revisions of the manuscript.

\section{Competing Interests}

$\mathrm{AB}$ and $\mathrm{JM}$ were involved in several projects funded by Catalysis S.L. using Ocoxin as a complement for anticancer treatments. ES is a current employee of Catalysis SL. The authors declare that there are no other nonfinancial interests.

\section{References}

1. Hwang J, Cho SH, Shim HJ, Lee SR, Ahn JS, Yang DH, et al. Phase II study of paclitaxel, cisplatin, and 5-fluorouracil combination chemotherapy in patients with advanced gastric cancer. J Korean Med Sci. 2008; 23:586-91.

2. Ergun Y, Acikgoz Y, Bal O, Ucar G, Dirikoc M, Caliskan Yildirim E. KRAS codon 12 and 13 mutations may guide the selection of irinotecan or oxaliplatin in first-line treatment of metastatic colorectal cancer. Expert Rev Mol Diagn. 2019; 19:1131-1140.

3. Tsujimoto A, Sudo K, Nakamura K, Kita E, Hara R, Takayama W, et al. Gemcitabine plus nab-paclitaxel for locally advanced or borderline resectable pancreatic cancer. Sci Rep. 2019; 9:16187.

4. Muto H, Kuzuya T, Ito T, Ishizu Y, Honda T, Ishikawa T, et al. Complete response of advanced hepatocellular carcinoma achieved by sorafenib dose re-escalation after failure of long-term low-dose-sorafenib treatment combined with transcatheter arterial chemoembolization: a case report. Clin J Gastroenterol. 2019; doi: 10.1007/s12328-019-01066-7.

5. Weber J, Glutsch V, Geissinger E, Haug L, Lock JF, Schneider F, et al. Neoadjuvant Immunotherapy with combined Ipilimumab and Nivolumab in Melanoma Patients with Primary or In-transit Disease. Br J Dermatol. 2019; doi: $10.1111 /$ bjd.18739.

6. Bess SN, Greening GJ, Muldoon TJ. Efficacy and clinical monitoring strategies for immune checkpoint inhibitors and targeted cytokine immunotherapy for locally advanced and metastatic colorectal cancer. Cytokine Growth Factor Rev. 2019; 49:1-9.

7. Takimoto $\mathrm{CH}$, Chao MP, Gibbs C, McCamish MA, Liu J, Chen JY, et al. The Macrophage 'Do not eat me' signal, CD47, is a clinically validated cancer immunotherapy target. Ann Oncol. 2019; 30:486-489.

8. Caraglia M, Correale P, Giannicola R, Staropoli N, Botta C, Pastina P, et al. GOLFIG Chemo-Immunotherapy in Metastatic Colorectal Cancer Patients. A Critical Review on a Long-Lasting Follow-Up. Front Oncol. 2019; 9: 1102.

9. Li T, Pan S, Gao S, Xiang W, Sun C, Cao W, et al. Diselenide-Pemetrexed Assemblies for Combined Cancer Immuno-, Radio-, and Chemotherapies. Angew Chem Int Ed Engl. 2020; 7:2700-2704.

10. Li H, Zhang Z, Duan X, Maimela NR, Yang S, Zhao X, et al. Efficacy of cascade-primed cell infusion as an adjuvant immunotherapy with concurrent chemotherapy for patients with non-small-cell lung cancer: A retrospective observational study with a 5-year follow-up. Cytotherapy. 2020; S1465-3249 (19): 30916-8.

11. Weijl NI, Elsendoorn TJ, Lentjes EG, Hopman GD, Wipkink-Bakker A, Zwinderman $\mathrm{AH}$, et al. Supplementation with antioxidant micronutrients and chemotherapy-induced toxicity in cancer patients treated with cisplatin-based chemotherapy: a randomized, double- blind, placebo-controlled study. Eur J Cancer. 2004; 40:1713-1723.

12. Gröber U. Antioxidants and Other Micronutrients in Complementary Oncology. Breast Care (Basel). 2009; 4:13-20.

13. Xu ZY, Jin CJ., Zhou CC, Wang ZQ, Zhou WD, Deng HB, et al. Treatment of advanced nonsmall cell lung cancer with Chinese herbal medicine by stages combined with chemotherapy. Cancer Res Clin Oncol. 2011; 137: 1117-1122.

14. Gillett J, Ientile C, Hiscock J, Plank A, Martin JM. Complementary and alternative medicine use in radiotherapy: what are patients using? J Altern Complement Med. 2012; 18:1014-20.

15. Brami C, Bao T, Deng G. Natural products and complementary therapies for chemotherapy-induced peripheral neuropathy: A systematic review. Crit Rev Oncol Hematol. 2016; 98: 325-334.

16. Huang S, You J, Wang K, Li Y, Zhang Y, Wei H, et al. N-Acetylcysteine Attenuates Cisplatin-Induced Acute Kidney Injury by Inhibiting the C5a Receptor. Biomed Res Int. 2019; 14: 4805853.

17. Onseng K, Johns NP, Khuayjarernpanishk T, Subongkot S, Priprem A, Hurst C, et al. Beneficial Effects of Adjuvant Melatonin in Minimizing Oral Mucositis Complications in Head and Neck Cancer Patients Receiving Concurrent Chemoradiation. J Altern Complement Med. 2017; 23:957-963.

18. Lin PC, Lee MY, Wang WS, Yen CC, Chao TC, Hsiao LT, et al. $\mathrm{N}$-acetylcysteine has neuroprotective effects against oxaliplatin-based adjuvant chemotherapy in colon cancer patients: preliminary data. Supportive Care in Cancer. 2006; 14:484-487.
19. Kono T, Mamiya N, Chisato N, Ebisawa Y, Yamazaki H, Watari J, et al. Efficacy of Goshajinkigan for peripheral neurotoxicity of oxaliplatin in patients with advanced or recurrent colorectal cancer. Evid Based Complement Alternat Med. 2011; 418481.

20. Yuan L, Hui-juan G, Jin-Chang H, Xiao-qin W. Clinical study of Jiawei Huangqi Guizhi Wuwu Decoction in preventing and treating peripheral neuro-sensory toxicity caused by oxaliplatin. Chin J Integr Med. 2006; 12:19-23.

21. Rolland V, Meyer F, Guitton MJ, Bussières R, Philippon D, Bairati I, et al. A randomized controlled trial to test the efficacy of trans-tympanic injections of a sodium thiosulfate gel to prevent cisplatin-induced ototoxicity in patients with head and neck cancer. J Otolaryngol Head Neck Surg. 2019; 48: 4.

22. Gylling B, Myte R, Schneede J, Hallmans G, Häggström J, Johansson I, et al. Vitamin B-6 and colorectal cancer risk: a prospective population-based study using 3 distinct plasma markers of vitamin B-6 status. Am J Clin Nutr. 2017; 105:897-904

23. Negri A, Naponelli V, Rizzi F, Bettuzzi S. Molecular Targets of Epigallocatechin-Gallate (EGCG): A Special Focus on Signal Transduction and Cancer. Nutrients. 2018; 10: E1936.

24. Soltanian S, Riahirad H, Pabarja A, Jafari E, Khandani BK. Effect of Cinnamic acid and FOLFOX in diminishing side population and downregulating cancer stem cell markers in colon cancer cell line HT-29. Daru. 2018; 1:19-29.

25. Gomez EV, Perez YM, Sanchez HV, Forment GR, Soler EA, Bertot LC, et al. Antioxidant and immunomodulatory effects of Viusid in patients with chronic hepatitis C. World J Gastroenterol. 2010; 16:2638-47.

26. Barnett MP, Cooney JM, Dommels YE, Nones K, Brewster DT, Park Z, et al. Modulation of colonic inflammation in $\operatorname{Mdr1a}(-/-)$ mice by green tea polyphenols and their effects on the colon transcriptome and proteome. J Nutr Biochem. 2013; 24:1678-90.

27. Khan R, Rehman MU, Khan AQ, Tahir M, Sultana S, et al. Glycyrrhizic acid suppresses 1,2-dimethylhydrazine-induced colon tumorigenesis in Wistar rats: Alleviation of inflammatory, proliferation, angiogenic, and apoptotic markers. Environ Toxicol. 2018; 33:1272-1283.

28. Yan T. Wang H, Cao L, Wang Q, Takahashi S, Yagai T, et al. Glycyrrhizin Alleviates Nonalcoholic Steatohepatitis via Modulating Bile Acids and Meta-Inflammation. Drug Metab Dispos. 2018; 46:1310-1319.

29. Luchtel RA, Bhagat T, Pradhan K, Jacobs WR Jr, Levine M, Verma A, et al. High-dose ascorbic acid synergizes with anti-PD1 in a lymphoma mouse model. Proc Natl Acad Sci U S A. 2020; 117:1666-1677.

30. Shafiee M, Ahmadnezhad M, Tayefi M, Arekhi S, Vatanparast H, Esmaeili H, et al. Depression and anxiety symptoms are associated with prooxidantantioxidant balance: A population-based study. J Affect Disord. 2018; 238:491-498

31. Uddin D, Islam M, Mahmood I, Ghosh A, Khatun R, Kundu S. Findings of the 3-Month Supportive Treatment with Oncoxin Solution Beside the Standard Modalities of Patients with Different Neoplastic Diseases. TAJ. 2018; 22:172-175.

32. Ruiz-Lorente $R$, Hernández-Durán $D$, García-Viamontes J, Lence-Anta J, Ortiz-Reyes R, Sanz-Navares E. Efficacy of Oncoxin-Viusid on the Reduction of Adverse Reactions to Chemotherapy and Radiotherapy in Patients Diagnosed with Cervical Cancer and Endometrial Adenocarcinoma. Journal of Cancer Therapy. 2020; 11:276-295.

33. Kaidarova DR, Kopp MV, Pokrovsky VS, Dzhugashvili M, Akimzhanova ZM, Abdrakhmanov RZ, et al. Multicomponent nutritional supplement Oncoxin and its influence on quality of life and therapy toxicity in patients receiving adjuvant chemotherapy. Oncol Lett. 2019; 18:5644-5652.

34. Malaguarnera G, Pennisi M, Bertino G, Motta M, Borzì AM, Vicari E, et al. Resveratrol in Patients with Minimal Hepatic Encephalopathy. Nutrients. 2018; 10: E329.

35. Yin C, Gou L, Liu Y, Yin X, Zhang L, Jia G, et al. Antidepressant-like effects of L-theanine in the forced swim and tail suspension tests in mice. Phytother Res. 2011; 25:1636-9.

36. Wakabayashi C, Numakawa T, Ninomiya M, Chiba S, Kunugi H. Behavioral and molecular evidence for psychotropic effects in L-theanine. Psychopharmacology (Berl). 2012; 219: 1099-109.

37. Zeni ALB, Camargo A, Dalmagro AP. Lutein prevents corticosterone-induced depressive-like behavior in mice with the involvement of antioxidant and neuroprotective activities. Pharmacol Biochem Behav. 2019; 179: 63-72.

38. Dantzer R. Cytokine, sickness behavior, and depression. Immunol Allergy Clin North Am. 2009; 29: 247-64.

39. Morris G, Reiche EMV, Murru A, Carvalho AF, Maes M, Berk M, et al. Multiple Immune-Inflammatory and Oxidative and Nitrosative Stress Pathways Explain the Frequent Presence of Depression in Multiple Sclerosis. Mol Neurobiol. 2018; 55: 6282-6306.

40. Hiles SA, Baker AL, de Malmanche T, Attia J. Interleukin-6, C-reactive protein and interleukin-10 after antidepressant treatment in people with depression: a meta-analysis. Psychol Med. 2012; 42: 2015-26.

41. Gobin V, Van Steendam K, Denys D, Deforce D. Selective serotonin reuptake inhibitors as a novel class of immunosuppressants. Int Immunopharmacol. 2014; 20: 148-56.

42. Vasileva LV, Saracheva KE, Ivanovska MV, Petrova AP, Sucouglu E, Murdjeva MA, et al. Beneficial Effect of Chronic Treatment with Extracts from Rhodiola Rosea L. and Curcuma Longa L. on the Immunoreactivity of Animals Subjected to a Chronic Mild Stress Model. Folia Med (Plovdiv). 2017; 59: 443-453. 
43. Vasileva LV, Saracheva KE, Ivanovska MV, Petrova AP, Marchev A, Georgiev MI, et al. Antidepressant-like effect of salidroside and curcumin on the immunoreactivity of rats subjected to a chronic mild stress model. Food Chem Toxicol. 2018; 121: 604-611.

44. Shen S, Jiang S. Chinese herbal medicines of supplementing Qi and nourishing Yin combined with chemotherapy for non-small cell lung cancer: A meta-analysis and systematic review. J Cell Biochem. 2019; 120(6): 8841-8848.

45. Chon Rivas I, Alert-Silva J, Alfonso G, Candanedo H, Cuervo Y, Mestre B, et al. Oncoxin-Viusid with Radiotherapy and Chemotherapy in Patients with Head and Neck Cancer: Results from a Phase II, Randomised, Double-Blind Study. J Cancer Sci Ther. 2018; 10: 10.

46. Ren X, Boriero D, Chaiswing L, Bondada S, St Clair DK, Butterfield DA. Plausible biochemical mechanisms of chemotherapy-induced cognitive impairment ("chemobrain"), a condition that significantly impairs the quality of life of many cancer survivors. Biochim Biophys Acta Mol Basis Dis. 2019; 1865: 1088-1097.

47. Richardson G, Dobish R. Chemotherapy induced diarrhea. J Oncol Pharm Pract. 2007; 13(4): 181-98.

48. Bao X, Wu J, Kim S, LoRusso P, Li J. Pharmacometabolomics Reveals Irinotecan Mechanism of Action in Cancer Patients. J Clin Pharmacol. 2019; 59: 20-34.

49. Lee CS, Ryan EJ, Doherty GA. Gastro-intestinal toxicity of chemotherapeutics in colorectal cancer: the role of inflammation. World J Gastroenterol. 2014; 20:3751-61.

50. Trifan OC., Durham WF, Salazar VS, Horton J, Levine BD, Zweifel BS, et al. Cyclooxygenase-2 inhibition with celecoxib enhances antitumor efficacy and reduces diarrhea side effect of CPT-11. Cancer Res. 2002; 62:5778-5784.

51. Sonis ST. Oral mucositis in head and neck cancer: risk, biology, and management. Am Soc Clin Oncol Educ Book. 2013; Doi:10.1200/EdBook_AM. 2013.33.e236.

52. Oronsky B, Goyal S, Kim MM, Cabrales P, Lybeck M, Caroen S, et al. A Review of Clinical Radioprotection and Chemoprotection for Oral Mucositis. Transl Oncol. 2018; 11:771-778.

53. Leitão RF, Ribeiro RA, Bellaguarda EA, Macedo FD, Silva LR, Oriá RB, et al. Role of nitric oxide on pathogenesis of 5-fluorouracil induced experimental oral mucositis in hamster. Cancer Chemother Pharmacol. 2007; 59:603-12.

54. Barbosa SC, Pereira VB, Wong DV, Santana AP, Lucetti LT, Carvalho LL, et al. Amifostine reduces inflammation and protects against 5-fluorouracil-induced oral mucositis and hyposalivation. Braz J Med Biol Res. 2019; 52:e8251.

55. Shumsky A, Evgeniy B, Sanz E, Petrovskiy F. Oncoxin nutritional supplement in the management of chemotherapy- and/or radiotherapy-associated oral mucositis. Mol Clin Oncol. 2019; 10:463-468.

56. Bak YK, Lampe JW, Sung MK. Effects of dietary supplementation of glucosamine sulfate on intestinal inflammation in a mouse model of experimental colitis. J Gastroenterol Hepatol. 2014; 29:957-63.

57. Patil K, Guledgud MV, Kulkarni PK, Keshari D, Tayal S. Use of Curcumin Mouthrinse in Radio-Chemotherapy Induced Oral Mucositis Patients: A Pilot Study. J Clin Diagn Res. 2015; 9:ZC59-62.

58. Normando AG, de Menêses AG, de Toledo IP, Borges GÁ, de Lima CL, Dos Reis PE, et al. Effects of turmeric and curcumin on oral mucositis: A systematic review. Phytother Res. 2019; 33:1318-1329.

59. Zhao H, Zhu W, Xie P, Li H, Zhang X, Sun X, et al. Phase I study of concurrent chemotherapy and thoracic radiotherapy with oral epigallocatechin-3-gallate protection in patients with locally advanced stage III non-small-cell lung cancer. Radiother Oncol. 2014; 110:132-6.

60. Zhao H, Xie P, Li X, Zhu W, Sun X, Sun X, et al. A prospective phase II trial of EGCG in treatment of acute radiation-induced esophagitis for stage III lung cancer. Radiother Oncol. 2015; 114:351-6.

61. Al-Mahtab M, Akbar SM, Khan MS, Rahman S. Increased survival of patients with end-stage hepatocellular carcinoma due to intake of ONCOXIN $₫$, a dietary supplement. Indian J Cancer. 2015; 52:443-6.

62. Lissoni P, Barni S, Mandalà M, Ardizzoia A, Paolorossi F, Vaghi M, et al. Decreased toxicity and increased efficacy of cancer chemotherapy using the pineal hormone melatonin in metastatic solid tumour patients with poor clinical status. Eur J Cancer. 1999; 35(12): 1688-92.

63. Lissoni P, Chilelli M, Villa S, Cerizza L, Tancini G. Five years' survival in metastatic non-small cell lung cancer patients treated with chemotherapy alone or chemotherapy and melatonin: a randomized trial. J Pineal Res. 2003; 35: $12-5$.

64. Arteta B, Lasuen N, Lopategi A, Sveinbjörnsson B, Smedsrød B, Vidal-Vanaclocha F. Colon carcinoma cell interaction with liver sinusoidal endothelium inhibits organ-specific antitumor immunity through interleukin-1-induced mannose receptor in mice. Hepatology. 2010; 51: 2172-82.

65. Benedicto A, Marquez J, Herrero A, Olaso E, Kolaczkowska E, Arteta B. Decreased expression of the $\beta 2$ integrin on tumor cells is associated with a reduction in liver metastasis of colorectal cancer in mice. BMC Cancer. 2017; 17: 827.

66. Konjević GM, Vuletić AM, Mirjačić Martinović KM, Larsen AK, Jurišić VB. The role of cytokines in the regulation of NK cells in the tumor environment. Cytokine. 2019; 117: 30-40.

67. Jiang X, Wang J, Deng X, Xiong F, Ge J, Xiang B, Wu X, Ma J, Li X, Li Y, Li G, Xiong W, Guo C, Zeng Z. Role of the tumor microenvironment in PD-L1/PD1-mediated tumor immune escape. Mol Cancer. 2019; 18: 10
68. Togashi $Y$, Shitara $K$, Nishikawa $H$. Regulatory $T$ cells in cancer immunosuppression - implications for anticancer therapy. Nat Rev Clin Oncol. 2019; 16: 356-371.

69. Grigorian A, O'Brien CB. Hepatotoxicity Secondary to Chemotherapy. J Clin Transl Hepatol. 2014; 2: 95-102.

70. Videla LA. Oxidative Stress Signaling Underlying Liver Disease and Hepatoprotective Mechanisms. World J Hepatol. 2009; 1: 72-8

71. Palipoch S, Punsawad C, Koomhin P, Suwannalert P. Hepatoprotective effect of curcumin and alpha-tocopherol against cisplatin-induced oxidative stress. BMC Complement. Altern. Med. 2014; 14: 111.

72. Yan Y, Mo Y, Zhang D. Magnesium isoglycyrrhizinate prevention of chemotherapy-induced liver damage during initial treatment of patients with gastrointestinal tumors. Zhonghua Gan Zang Bing Za Zhi. 2015; 23: 204-208 (In Chinese).

73. Dicato M, Plawny L, Diederich M. Anemia in cancer. Ann Oncol; 2010; 21: 167-72.

74. Fuchs-Tarlovsky V, Rivera MA, Altamirano KA, Lopez-Alvarenga JC, Ceballos-Reyes GM. Antioxidant supplementation has a positive effect on oxidative stress and hematological toxicity during oncology treatment in cervical cancer patients. Support Care Cancer. 2013; 21: 1359-1363.

75. Hernández-García S, González V, Sanz E, Pandiella A. Effect of Oncoxin Oral Solution in HER2-Overexpressing Breast Cancer. Nutr Cancer. 2015; 67: 1159-69.

76. Márquez J, Mena J, Hernandez-Unzueta I, Benedicto A, Sanz E, Arteta B et al. Ocoxin $₫$ oral solution slows down tumor growth in an experimental model of colorectal cancer metastasis to the liver in Balb/c mice. Oncol Rep. 2016; 35: 1265-72.

77. Díaz-Rodríguez E, Hernández-García S, Sanz E, Pandiella A. (2016). Antitumoral effect of Ocoxin on acute myeloid leukemia. Oncotarget. 2016; 7: 6231-42.

78. Hernandez-Unzueta I, Benedicto A, Olaso E, Sanz E, Viera C, Arteta B et al. Ocoxin oral solution ${ }^{\circledR}$ as a complement to irinotecan chemotherapy in the metastatic progression of colorectal cancer to the liver. Oncol Lett. 2017; 13: 4002-4012.

79. Díaz-Rodríguez E, El-Mallah AM, Sanz E, Pandiella A. Antitumoral effect of Ocoxin in hepatocellular carcinoma. Oncol Lett. 2017; 4: 1950-1958.

80. Díaz-Rodríguez E, Sanz E, Pandiella A. Antitumoral effect of Ocoxin, a natural compound-containing nutritional supplement, in small cell lung cancer. Int J Oncol. 2018; 53: 113-123.

81. Hernandez-Unzueta I, Benedicto A, Romayor I, Herrero A, Sanz E, Arteta B et al. Ocoxin Oral Solution Exerts an Antitumoral Effect in Pancreatic Cancer and Reduces the Stromal-Mediated Chemoresistance. Pancreas. 2019; 48: 555-567.

82. Rothe J, Wakileh M, Dreißiger K, Weber H. The flavonoid beverage Haelan 951 induces growth arrest and apoptosis in pancreatic carcinoma cell lines in vitro. BMC Complement Altern Med. 2015; 15: 212

83. Rahmani AH, Al Shabrmi FM, Allemailem KS, Aly SM, Khan MA. Implications of Green Tea and Its Constituents in the Prevention of Cancer via the Modulation of Cell Signalling Pathway. Biomed Res Int. 2015; 925640.

84. Sun C, Zhang S, Liu C, Liu X. Curcumin Promoted miR-34a Expression and Suppressed Proliferation of Gastric Cancer Cells. Cancer Biother Radiopharm. 2019; 34: 634-641.

85. Bi YL, Min M, Shen W, Liu Y. Genistein induced anticancer effects on pancreatic cancer cell lines involves mitochondrial apoptosis, G0/G1cell cycle arrest and regulation of STAT3 signalling pathway. Phytomedicine. 2018; 39: $10-16$

86. Hsiao YC, Peng SF, Lai KC, Liao CL, Huang YP, Lin CC, et al. Genistein induces apoptosis in vitro and has antitumor activity against human leukemia HL-60 cancer cell xenograft growth in vivo. Environ Toxicol. 2019; 34: 443-456.

87. Cianfruglia L, Minnelli C, Laudadio E, Scirè A, Armeni T. Side Effects of Curcumin: Epigenetic and Antiproliferative Implications for Normal Dermal Fibroblast and Breast Cancer Cells. Antioxidants (Basel). 2019: 8: pii: E382.

88. Bhattacharyya S, Mandal D, Saha B, Sen GS, Das T, Sa G. Curcumin prevents tumor-induced $\mathrm{T}$ cell apoptosis through Stat-5a-mediated Bcl-2 induction. J Biol Chem. 2007; 282:15954-64.

89. Campbell FC, Collett GP. Chemopreventive properties of curcumin. Future Oncol. 2005; 1:405-14.

90. Choudhuri T, Pal S, Das T, Sa G. Curcumin selectively induces apoptosis in deregulated cyclin D1-expressed cells at G2 phase of cell cycle in a p53-dependent manner. J Biol Chem. 2005; 280:20059-6.

91. Sharma RA, Gescher AJ, Steward WP. Curcumin: the story so far. Eur J Cancer. 2005; 41:1955-68.

92. Park $\mathrm{C}$, Cha $\mathrm{HJ}$, Lee $\mathrm{H}$, et al. Induction of $\mathrm{G} 2 / \mathrm{M}$ Cell Cycle Arrest and Apoptosis by Genistein in Human Bladder Cancer T24 Cells through Inhibition of the ROS-Dependent PI3k/Akt Signal Transduction Pathway. Antioxidants (Basel). 2019; 8: pii: E327.

93. Kim W, Lee WB, Lee J, Min BI, Lee H, Cho SH. Traditional herbal medicine as adjunctive therapy for nasopharyngeal cancer: a systematic review and meta-analysis. Integr Cancer Ther. 2015; 14:212-20.

94. Bahmani F, Esmaeili S, Bashash D, Dehghan-Nayeri N, Mashati P, Gharehbaghian A. Centaurea albonitens extract enhances the therapeutic effects of Vincristine in leukemic cells by inducing apoptosis. Biomed Pharmacother. 2018; 99:598-607.

95. Cai D, He K, Chang S, Tong D, Huang C. MicroRNA-302b Enhances the Sensitivity of Hepatocellular Carcinoma Cell Lines to 5-FU via Targeting Mcl-1 and DPYD. Int J Mol Sci. 2015; 16:23668-82. 
96. Chen Z, Penet MF, Krishnamachary B, Banerjee SR, Pomper MG, Bhujwalla ZM. PSMA-specific theranostic nanoplex for combination of TRAIL gene and 5-FC prodrug therapy of prostate cancer. Biomaterials. 2016; 80:57-67.

97. Deveci HA, Nazıroğlu M, Nur G. 5-Fluorouracil-induced mitochondrial oxidative cytotoxicity and apoptosis are increased in MCF-7 human breast cancer cells by TRPV1 channel activation but not Hypericum perforatum treatment. Mol Cell Biochem. 2018; 439:189-198.

98. Zhou X, Wang W, Li P, Zheng Z, Tu Y, Zhang Y, et al. (2016). Curcumin Enhances the Effects of 5-Fluorouracil and Oxaliplatin in Inducing Gastric Cancer Cell Apoptosis Both In vitro and In vivo. Oncol Res. 2016; 23:29-34.

99. La X, Zhang L, Li Z, Li H, Yang Y. (-)-Epigallocatechin Gallate (EGCG) Enhances the Sensitivity of Colorectal Cancer Cells to 5-FU by Inhibiting GRP78/NF-kB/miR-155-5p/MDR1 Pathway. J Agric Food Chem. 2019; 67:2510-2518.

100. Zhu X, Shen H, Yin X, Long L, Xie C, Liu Y, et al. miR-186 regulation of Twist1 and ovarian cancer sensitivity to cisplatin. Oncogene. 2016; 35: 323-32.

101. Ouyang M, Luo Z, Zhang W, Zhu D, Lu Y, Wu J et al. Protective effect of curcumin against irinotecan-induced intestinal mucosal injury via attenuation of NF-KB activation, oxidative stress and endoplasmic reticulum stress. Int J Oncol. 2019; 54: 1376-1386.

102. Williamson G, Coppens P, Serra-Majem L, Dew T. Review of the efficacy of green tea, isoflavones and aloe vera supplements based on randomised controlled trials. Food Funct. 2011; 2:753-9.

103. Alfarouk KO, Stock CM, Taylor S, Walsh M, Muddathir AK, Verduzco D, et al. Resistance to cancer chemotherapy: failure in drug response from ADME to P-gp. Cancer Cell Int. 2015; 15: 71.

104. Alaoui-Jamali MA, Dupré I, Qiang H. Prediction of drug sensitivity and drug resistance in cancer by transcriptional and proteomic profiling. Drug Resist Updat. 2004; 7: 245-55.

105. Wang J, Qian Z, Dandan W, Sujin Y, Siying Z, Hanzi X. et al. Microenvironment-induced TIMP2 loss by cancer-secreted exosomal miR4443 promotes liver metastasis of breast cancer. J Cell Physiol. 2020.

106. Peinado H, Zhang H, Matei IR, Costa-Silva B, Hoshino A, Rodrigues G. et al. Pre-metastatic niches: organ-specific homes for metastases. Nat Rev Cancer. 2017; 17:302-317.

107. Conti I, Varano G, Simioni C, Laface I, Milani D, Rimondi E. et al. (2020). miRNAs as Influencers of Cell-Cell Communication in Tumor Microenvironment. Cells. 2020; 9: 220.

108. Melcher V, Graf M, Interlandi M, Moreno N, de Faria FW, Kim SN et al. Macrophage-tumor cell interaction promotes ATRT progression and chemoresistance. Acta Neuropathol. 2020; 139: 913-936.

109. Savardashtaki A, Shabaninejad Z, Movahedpour A, Sahebnasagh R, Mirzaei $\mathrm{H}$, Hamblin MR. miRNAs derived from cancer-associated fibroblasts in colorectal cancer. Epigenomics. 2019; 11:1627-1645.

110. Quail DF, Joyce JA. Microenvironmental regulation of tumor progression and metastasis. Nat Med. 2013; 19: 1423-37.

111. Nakasone ES, Askautrud HA, Kees T, Park JH, Plaks V, Ewald A. et al. Imaging tumor-stroma interactions during chemotherapy reveals contributions of the microenvironment to resistance. Cancer Cell. 2012; 21: 488-503.

112. Wang JP, Tang YY, Fan CM, Guo C, Zhou YH, Li Z et al. The role of exosomal non-coding RNAs in cancer metastasis. Oncotarget. 2017; 9: 12487-12502.

113. Quante M, Tu SP, Tomita H, Gonda T, Wang SS, Takashi S. et al. Bone marrow-derived myofibroblasts contribute to the mesenchymal stem cell niche and promote tumor growth. Cancer Cell. 2011; 19: 257-72.

114. Kalluri, R. The biology and function of fibroblasts in cancer. Nat Rev Cancer. 2016; 16: 582-98.

115. Li X, Li Q Yu X, Li H, Huang G. Reverse of microtubule-directed chemotherapeutic drugs resistance induced by cancer-associated fibroblasts in breast cancer. Onco Targets Ther. 2019; 12: 7963-7973.

116. Olaso E, Santisteban A, Bidaurrazaga J, Gressner AM, Rosenbaum J, Vidal-Vanaclocha F. Tumor-dependent activation of rodent hepatic stellate cells during experimental melanoma metastasis. Hepatology.1997; 26: 634-42.

117. Liepelt A, Tacke F. Stromal cell-derived factor-1 (SDF-1) as a target in liver diseases. Am J Physiol Gastrointest Liver Physiol. 2016; 311:G203-9.

118. Olaso E, Salado C, Egilegor E, Gutierrez V, Santisteban A, Sancho-Bru P. et al. Proangiogenic role of tumor-activated hepatic stellate cells in experimental melanoma metastasis. Hepatology. 2003; 37:674-85.

119. Benedicto A, Romayor I, Arteta B. CXCR4 receptor blockage reduces the contribution of tumor and stromal cells to the metastatic growth in the liver. Oncol Rep. 2018; 39:2022-2030.

120. Benedicto A, Herrero A, Romayor I, Marquez J, Smedsrød B, Olaso E, et al. Liver sinusoidal endothelial cell ICAM-1 mediated tumor/endothelial crosstalk drives the development of liver metastasis by initiating inflammatory and angiogenic responses. Sci Rep. 2019; 9:13111.

121. Ishii N, Araki K, Yokobori T, Hagiwara K, Gantumur D, Yamanaka T. et al. Conophylline suppresses pancreatic cancer desmoplasia and cancerpromoting cytokines produced by cancer-associated fibroblasts. Cancer Sci. 2019; 110:334-344.

122. Mantovani A, Bottazzi B, Colotta F, Sozzani S, Ruco L. The origin and function of tumor-associated macrophages. Immunol Today. 1992; 13:265-70.

123. Mantovani A, Sozzani S, Locati M, Allavena P, Sica A. Macrophage polarization: tumor-associated macrophages as a paradigm for polarized M2 mononuclear phagocytes. TRENDS in Immunology. 2002; 23:549-55.
124. Dey P, Kim JB, Chitchumroonchokchai C, Li J, Sasaki GY, Olmstead BD et al. Green tea extract inhibits early oncogenic responses in mice with nonalcoholic steatohepatitis. Food Funct. 2019; 10:6351-6361.

125. Hernández-San Miguel E, Gargini R, Cejalvo T, Segura-Collar B, NúñezHervada P, Hortigüela R. et al. Ocoxin Modulates Cancer Stem Cells and M2 Macrophage Polarization in Glioblastoma. Oxid Med Cell Longev. 2019; 2019:9719730.

126. Zhang Y, Choksi S, Chen K, Pobezinskaya Y, Linnoila I, Liu ZG. ROS play a critical role in the differentiation of alternatively activated macrophages and the occurrence of tumor-associated macrophages. Cell Res. 2013; 23:898-914.

127. Xue N, Zhou Q, Ji M, Jin J, Lai F, Chen J. et al. Chlorogenic acid inhibits glioblastoma growth through repolarizating macrophage from M2 to M1 phenotype. Sci Rep. 2017; 7:39011. 